\title{
Efektifitas Pelayanan Kartu Keluarga (KK) Dan Surat Pindah Pada Tahun 2020 di Kecamatan Wlingi Kabupaten Blitar
}

\section{Effectiveness of Family Card Services (KK) and Moving Letter In 2020 in Wlingi District, Blitar Regency}

\author{
Sutowo ${ }^{1}$, Amira Rizki \\ ${ }^{1}$ Fakultas Ilmu Sosial dan Ilmu Politik, Univ. Islam Balitar \\ Jl. Majapahit No. 2 - 4, Blitar, Indonesia \\ ${ }^{2}$ Fakultas Ilmu Sosial dan Ilmu Politik, Univ. Islam Balitar \\ Jl. Majapahit No. 2 - 4, Blitar, Indonesia \\ Email: sutowoss@yahoo.com
}

\begin{abstract}
ABSTRAK
Reformasi dalam pelayanan publik saat ini dalam rangka mewujudkan sistem pelayanan masyarakat pada kantor kecamatan Wlingi Kabupaten Blitar bagi masyarakat perlu diusahakan peningkatan pelayanan yang cepat, tepat dan akurat baik secara langsung maupun tak langsung demi terciptanya pelayanan yang baik dan memberikan kepuasan pada masyarakat. Efektifitas Kartu Keluarga dan Surat pindah sangat dibutuhkan dalam menentukan penilaian kepuasan masyarakat terhadap pelayanan yang dilakukan oleh Kantor Kecamatan Wlingi. Metode penelitian yang digunakan adalah kualitatif yang bersifat deskriptif, yaitu (1) Desain Penelitian (2) Obyek yang diteliti (3) Sumber Data (4) Teknik Pengumpulan Data (5) Teknik Analisis Data dan Keabsahan Data. Hasil efektifitas yang diperoleh dari enam obyek yang diteliti sebesar 96\% masyarakat sudah memahami dan mengetahui tentang prodesur pelayan yang dilakukan oleh Kecamatan Wlingi, 96\% masyarakat menyatakan bahwa waktu penyelesaian Kartu Keluarga dan Surat pindah sangat cepat dalam hitungan menit, 93\% masyarakat menyatakan bahwa biaya pelayanan di Kecamatan Wlingi sudah tidak ada (gratis), 60\% masyarakat menyatakan bahwa produk pelayanan Kartu Keluarga dan Surat Pindah sangat tidak awet dan tidak efisen untuk dibawa kemana-kemana, 53\% masyarakat cukup nyaman dengan sarana dan prasarana yang ada di pelayanan Kecamatan Wlingi, dan $76 \%$ masyarakat puas dengan kompetensi petugas pemberi pelayanan yang cepat, tepat, cakap, dan keramahan yang diberikan. Dari hasil efektifitas pelayanan yang peneliti jabarkan, masih terdapat beberapa kedala yang ada, dan dapat menghambat efektifitas pelayanan yang ada di Kantor Kecamatan Wlingi.
\end{abstract}

Kata Kunci : Kartu Keluarga, Surat Pindah, Efektifitas, Kendala Efektifitas

\section{ABSTRACT}

Reformation in public services is currently needed in order to realize a community service system at the Wlingi sub-district office in Blitar Regency for the community, efforts should be made to improve services that are fast, precise 
and accurate both directly and indirectly in order to create good service and provide satisfaction to the community. The effectiveness of the Family Card and the Letter moved is very much needed in determining the assessment of community satisfaction with the services carried out by the Wlingi District Office. The research method used is a descriptive qualitative research method, namely (1) Research Design (2) Researched Objects (3) Data Sources (4) Collection Techniques Data (5) Data Analysis Techniques and Data Validity. The results of the effectiveness of the researchers obtained from six objects in which the researchers carefully obtained results as much as $96 \%$ of the people understood and learned about the servants' productions carried out by Wlingi Subdistrict, 96\% of the people stated that the Family and Letter Card completion times moved very quickly in minutes, $93 \%$ of the people stated that the cost of service in Wlingi District was gone (free), $60 \%$ of the people stated that the Family Card and Moving Mail service products were very durable and inefficient to carry around, $53 \%$ of the community was comfortable with facilities and infrastructure in the Wlingi District service, and 76\% of the community were satisfied with the competency of the service provider who was fast, precise, capable, and friendly. From the results of the effectiveness of the services that the researchers describe, there is a problems that can hamper the effectiveness of services in the Wlingi District Office.

Keywords: Family Cards, Moving Letters, Effectiveness, Effectiveness Constraint

\section{PENDAHULUAN}

Reformasi dalam pelayanan publik saat ini dibutuhkan untuk mendudukan pelayanan dan yang dilayani pada pengertian yang sesungguhnya. Pelayanan yang seharusnya ditujukan untuk masyarakat umum, namun terkadang sebaliknya pelayanan masyarakat terhadap negara, karena pada hakikatnya negara ini berdiri untuk kepentingan masyarakat umum. Artinya birokrat seharusnya memberikan pelayanan yang terbaik untuk masyarakat, dalam hal ini pelayanan yang diberikan oleh para birokrat adalah tidak memandang siapa yang dilayaninya apakah itu masyarakat biasa atau dari kalangan masyarakat birokrat itu sendiri, agar tidak ada sikap diskriminasi, dan melayani dengan tepat waktu yang telah ditentukan sehingga masyarakat tidak menunggu lama atas pelayanan yang diinginkan.

Dalam rangka mewujudkan sistem pelayanan masyarakat pada kantor kecamatan Wlingi Kabupaten Blitar bagi masyarakat perlu diusahakan peningkatan pelayanan yang cepat, tepat dan akurat baik secara langsung maupun tak langsung demi terciptanya pelayanan yang baik dan memberikan kepuasan pada masyarakat. Menurut Tjiptono (2004:59) maka dapat diindikasikan bahwa 
sebuah kualitas pelayanan yang diharapkan oleh masyarakat sebagai penerima layanan mengharapkan tingkat keunggulan dari setiap jasa pelayanan yang didapat dari pelayanan yang didapatkan sebelumnya. Bila pelayanan yang diberikan melampaui harapan dari pelanggan maka kualitas pelayanan yang diberikan akan mendapatkan persepsi yang ideal dari para penerima pelayanan.

Khususnya Kecamatan Wlingi Kabupaten Blitar dalam rangka mewujudkan cita-cita memberikan pelayanan prima bagi masyarakat yang meliputi pelayanan pengurusan Kartu Keluaga (KK), dan pengurusan Surat Pindah. Pelayanan yang memenuhi standar kualitas adalah suatu pelayanan yang sesuai denan harapan dan kepuasan pelanggan atau masyarakat (Maddy, 2009: 8). Secara sederhana, pelayanan prima (excellent service) adalah suatu pelayanan yang terbaik dalam memenuhi harapan dan kebutuhan pelanggan.

Prosedur dalam pengurusan Kartu Keluarga dan Surat Pindah perlu di cermati oleh masyarakat agar tidak adanya kesalahan dan tidak dapat menimbulkan suatu kasus di kemudian hari. Salah satu keluhan yang sering terdengar adalah selain berbelit-belit akibat birokrasi yang kaku, juga perilaku oknum aparat yang sering kurang bersahabat. Realita tersebut memerlukan kepedulian aparatur pemerintah agar masyarakat memperoleh layanan prima.

\section{METODE PENELITIAN}

Segala prosedur aktifitas penelitian yang peneliti lakukan untuk menyusun penelitian ini, menunjukkan bahwa peneliti menggunakan metode penelitian kualitatif yang bersifat deskriptif. Menurut Bogdan dan Taylor (Lexy J. Moleong, 2007:3) Metodologi kualitatif merupakan prosedur penelitian yang menghasilkan data deskriptif berupa kata-kata tertulis atau lisan orang-orang dari perilaku yang dapat diamati. Penelitian deskriptif ini dimaksudkan untuk mengetahui efektivitas pelayanan Kartu Keluarga dan Surat Pindah di Kecamatan Wlingi Kabupaten Blitar menggambarkan keadaan yang sebenarnya atau apa adanya.

Pelaksanaan program pelayanan Kartu Keluarga dan Surat Pindah yang diwujudkan oleh pelayanan publik yaitu kelompok pelayanan jasa. Standar pelayanan publik sebagai obyek yang diteliti untuk menganalisa pelayanan Kartu Keluarga dan Surat Pindah berupa: 
1. Prosedur pelayanan

2. Waktu penyelesaian

3. Biaya pelayanan

4. Produk pelayanan

5. Sarana dan prasarana

6. Kompetensi petugas pemberi pelayanan

Teknik pengumpulan data pada penelitian ini dilakukan dengan 3 teknik pengumpulan data berupa wawancara, observasi, dan dokumentasi. Pengumpulan data dalam penelitian kualitatif dilakukan sampai pada tingkat kejenuhan (saturated) informan awal, mereka yang menguasai data-data yang dipilih, calon ini akan berkembang ke calon-calon berikutnya. Informasi berikutnya dipilih dengan cara bola salju (snowball), informan berikutnya ditentukan bergilir sampai pada tingkat kejenuhan (saturated) artinya tidak ada lagi variasi jawaban dari informan.

Analisis yang dipergunakan dalam penelitian ini adalah teknik analisis kualitatif dari Miles dan Huberman (1992: 15-21), model analisis interaktif dan analisis komparatif, yaitu membandingkan hasil-hasil penelitian dengan temuantemuan penelitian terdahulu. Proses analisis ini dilakukan melalui tiga langkah: data yang muncul berwujud kata-kata dari hasil observasi, wawancara, intisari dokumen, pita rekaman dan sebagainya. Analisis terdiri dari tiga alur kegiatan secara bersamaan yaitu reduksi data, penyajian data, dan penarikan kesimpulan/verifikasi.

\section{HASIL DAN PEMBAHASAN}

Efetkifitas pelayanan Kartu Keluarga dan Surat Pindah di Kecamatan Wlingi memiliki 6 (enam) indikator yang dapat mengukur tingkat efektif pelayanan Kartu keluarga dan Surat pindah di kecamatan Wlingi, yang meliputi:

1. Prosedur Pelayanan

96\% masyarakat yang mengurus Kartu Keluarga dan Surat Pindah berpendapat bahwa prosedur pelayanan yang ada di Kantor Kecamatan Wlingi sudah sesuai dengan pearutan yang ada dan sudah sesuai dengan S.O.P yang ada, 
serta mudahnya prosedur yang ada sehingga memudahkan masyarakat untuk mengurus Kartu Keluarga dan Surat Pindah.

2. Waktu Penyelesaian

96\% masyarakat yang mengurus Kartu Keluarga dan Surat Pindah berpendapat bahwa Waktu yang dibutuhkan untuk kepengurusan Kartu Keluarga dan Surat Pindah sudah sesuai dengan S.O.P yang ada serta tidak membutuhkan waktu yang sangat lama dalam pengurusannya.

3. Biaya Pelayanan

93\% masyarakat yang mengurus Kartu Keluarga dan Surat Pindah berpendapat bahwa di Kantor Kecamatan Wlingi tidak ada pemungutan biaya dalam pengurusan Kartu Keluarga dan Surat Pindah, dan tidak adanya biaya tambahan untuk pengurusan Kartu Keluarga dan Surat Pindah di kantor Kecamatan Wlingi.

4. Produk Pelayanan

$60 \%$ masyarakat yang mengurus Kartu Keluarga dan Surat Pindah berpendapat bahwa produk pelayanan Kartu Keluarga dan Surat Pindah bahan atau material yang digunakan tidak kuat dan tahan lama, mudah sekali robek dan material atau bahan yang digunakan tidak tahan terhadap air.

5. Sarana dan Prasarana

$53 \%$ masyarakat yang mengurus Kartu Keluarga dan Surat Pindah berpendapat bahwa sarana dan prasarana di Kantor Kecamatan Wlingi cukup nyaman untuk masyarakat yang mengurus Kartu Keluarga dan Surat pindah, cukup aman untuk tingkat keamanannya, dan sangat cukup untuk tempat duduk bagi masyarakat pemohon Kartu Keluarga dan Surat pindah menunggu yang akan melakukan pengurusan.

6. Kompetensi Petugas Pemberi Pelayanan

$76 \%$ masyarakat yang mengurus Kartu Keluarga dan Surat Pindah berpendapat bahwa kompetensi petugas pemberi pelayanan sudah memenuhi S.O.P yang ada dengan selalu tepat waktu dalam dating dan pelayanan, sopan dan ramah dalam pemberian pelayanan, dan sangat cepat dalam pelayanan dalam pengurusan Kartu Keluarga dan Surat pindah.

\section{Hambatan-Hambatan dalam Pelayanan}

Adanya beberapa hambatan atau kendala yang terjadi di dalam pelayanan Kartu Keluarga dan Surat Pindah di Kecamatan Wlingi adalah banyaknya 
masyarakat yang tidak mengetahui persyaratan yang harus dipenuhi untuk perubahan, pembaharuan dan pencetakan Kartu Keluarga serta persyaratan mengurus Surat Pindah dan baru mengetahui persyaratan ketika sudah sampai di Kantor Kecamatan. Masyarakat yang dari desa atau kelurahan yang jauh dari Kantor Kecamatan harus menempuh jarak sangat jauh dan dua kali bolak balik untuk mengurus jika persyaratan kurang atau tidak dibawa. Kurangnya sosialisasi yang dilakukan Kantor Kecamatan kepada Kantor Desa atau Kantor Kelurahan untuk memberikan informasi kepada masyarakat yang akan mengurus Kartu Keluarga dan Surat Pindah dan berbagai persyaratan yang harus dibawa serta di penuhi.

Trouble yang terjadi pada SIAK juga menjadi suatu hambatan yang sangat mempengaruhi dalam pengurusan Kartu Keluarga dan Surat Pindah karena data yang akan dirubah tidak bisa diakses, sehingga pemohon harus menunggu hingga masalah SIAK selesai, dan menunggu hingga normal kembali serta tidak jarang Kartu Keluarga dan Surat pindah tercetak esok harinya.

\section{KESIMPULAN DAN SARAN}

Dari hasil rata-rata 6 (enam) indikator yang dapat mengukur tingkat efektif pelayanan Kartu keluarga dan Surat pindah di kecamatan Wlingi dapat disimpulkan bahwa masyarakat memperoleh pelayanan pelayan publik yang cukup berkualitas, tidak berbelit-belit, lambat, mahal, dan membuat masyarakat lelah untuk menerima pelayanan. adapun saran yang dapat diberikan oleh peneliti ialah :

1. Lebih ditingkatkannya komunikasi dan informasi dari Kantor Kecamatan kepada masyarakat melalui aparat desa atau kelurahan tentang administrasi kependudukan tentang Kartu Keluarga dan Surat Pindah sehingga masyarakat lebih memahami dan lebih mengetahui persyaratan dan hal - hal yang di butuhkan untuk mengurus Kartu Keluarga dan Surat pindah.

2. Kecamatan sebaiknya lebih aktif memperbaharui berita atau persyaratan dalam kepengurusan administrasi kependudukan agar masyarakat mengetahui berita atau syarat terbaru, dengan melalui papan informasi yang ada di Kantor Kecamatan, dan di Kantor Desa atau Kelurahan, dan juga di website Kecamatan Wlingi.

3. Di era globalisasi dan teknologi Kecamatan harus mengembangkan pelayanan berbasis teknologi dan mengikuti perkembangan zaman guna lebih memepermudah, menghemat, dan mengefesiensi waktu yang dibutuhkan untuk kepengurusan administrasi kependudukan dengan cara membuat pelayanan online 24 jam dengan menghubungi nomor yang sudah ditentukan yang bisa digunakan oleh masyarakat yang ingin mengetahui informasi tentang Kartu Keluarga dan Surat pindah dengan lebih cepat. 
4. Masyarakat bisa memanfaatkan SKP (Survey Kepuasan Pelanggan) android yang ada di Kantor Kecamatan terhadap pelayanan Kartu Keluarga dan Surat Pindah, dan dapat juga memberikan kritik dan saran untuk pelayanan.

\section{DAFTAR PUSTAKA}

Maddy, Khairul. (2009). Hakikat dan Pengertian Pelayanan Prima. Jakarta: Chama Digit. hal.8

Miles, B. Mathew dan Michael Huberman. (1992). Analisis Data Kualitatif Buku Sumber Tentang Metode-metode Baru. Jakarta: UIP. hal.15-21.

Moleong, Lexy J. (2007). Metodologi Penelitian Kualitatif. Bandung: PT Remaja Rosdakarya Offset. hal.3

Tjiptono. (2004). Manajemen Jasa. Yogyakarta: Andi offset. hal.59 